\title{
BRPKM
}

Buletin Riset Psikologi dan Kesehatan Mental

http://e-journal.unair.ac.id/index.php/BRPKM

e-ISSN: 2776-1851

ARTIKEL PENELITIAN

\section{Pengaruh Self-compassion terhadap Resiliensi Orang Tua dari Anak dengan Autism Spectrum Disorder (ASD)}

\author{
RACHMA SETYA ISFANI \& PRAMESTI PRADNA PARAMITA* \\ Fakultas Psikologi Universitas Airlangga
}

\begin{abstract}
ABSTRAK
Orang tua dari anak dengan ASD menghadapi tantangan yang signifikan, yang dapat menimbulkan stres, depresi, dan efek buruk pada perkembangan anak. Di sisi lain, terdapat orang tua yang mampu bangkit dari situasi sulit, memiliki kesejahteraan psikologis yang baik, dan penerimaan terhadap kondisi anak. Penelitian ini bertujuan untuk menguji pengaruh self-compassion terhadap resiliensi orang tua dari anak dengan ASD dan mengetahui perbedaan rata-rata self-compassion dan resiliensi berdasarkan faktor demografis. Pengumpulan data dilakukan menggunakan alat ukur Self-compassion Scale dan Brief Resilience Scale. Analisis data dilakukan dengan uji regresi linear sederhana, independent sample t-test, dan ANOVA menggunakan SPSS versi 22 for Windows. Hasil penelitian menunjukkan bahwa selfcompassion berpengaruh signifikan dan positif terhadap resiliensi. Terdapat perbedaan rata-rata selfcompassion berdasarkan usia, jenis kelamin, dan keikutsertaan orang tua dalam komunitas. Terdapat perbedaan rata-rata resiliensi berdasarkan tingkat pendidikan orang tua dan tingkat keparahan gejala ASD.
\end{abstract}

Kata kunci: autism spectrum disorder, orang tua, resiliensi, self-compassion

\begin{abstract}
Parents of children with ASD face significant challenges, which can lead to stress, and adverse effects on child development. But, there are parents who are able to rise from difficult situations, have good psychological well-being, and accept their children's condition. This study aims to examine the effect of self-compassion toward resilience on parents of children with ASD and determine the difference average of self-compassion and resilience based on demographic factors. Data was collected selfcompassion scale and brief resilience scale. Data analysis was performed by simple linear regression test, independent sample t-test, and ANOVA using SPSS version 22 for Windows. The results showed that self-compassion had a significant and positive effect on resilience. There are differences average of self-compassion based on age, gender, and parental participation in the community. There are differences average of resilience based on level education of parents and symptoms severity of ASD.
\end{abstract}

Keywords: autism spectrum disorder, parents, resilience, self-compassion

Buletin Penelitian Psikologi dan Kesehatan Mental (BRPKM), 2021, Vol. 1(2), 1331-1346

*Alamat korespondensi: Fakultas Psikologi Universitas Airlangga, Kampus B Universitas Airlangga Jalan Airlangga 4-6 Surabaya 60286. Surel: pramesti.paramita@psikologi.unair.ac.id

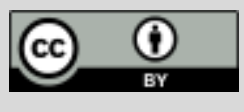

Naskah ini merupakan naskah dengan akses terbuka dibawah ketentuan the Creative Common Attribution License (CC-BY-4.0) (http://creativecommons.org/licenses/by/4.0), sehingga penggunaan, distribusi, reproduksi dalam media apapun atas artikel ini tidak dibatasi, selama sumber aslinya disitir dengan baik. 


\section{PEN D A H U L U A N}

Autism spectrum disorder (ASD) merupakan gangguan perkembangan yang ditandai dengan kurangnya komunikasi sosial, interaksi sosial yang bersifat persisten, serta adanya pola perilaku dan aktivitas yang bersifat repetitif yang gejalanya muncul sebelum anak berusia 3 tahun (American Psychiatric Association, 2015; Bernier \& Gerdts, 2010; Lindgren \& Doobay, 2011). Sejumlah anak dengan ASD juga memperlihatkan gangguan dalam fungsi kognitif, sensorik dan motorik, perilaku yang agresif dan berbahaya, serta gangguan tidur dan pola makan (Hallahan \& Kauffman, 2011). Adanya gejala-gejala tersebut membuat anak dengan ASD mengalami kesulitan mengembangkan keterampilan sosial yang merupakan hal penting bagi anak agar menjadi individu yang mandiri (Thompson, 2013).

Jumlah anak dengan ASD diperkirakan terus meningkat setiap tahunnya. Centre for Disease Control and Prevention (CDC), Autism and Developmental Disability Monitoring (ADDM), dan National Survey of Children's Health (NSCH) menyebutkan terdapat peningkatan prevalensi anak dengan ASD di Amerika sejak tahun 2000 hingga 2018 (Centers for Disease Control and Prevention, 2020; Kogan, 2018). Di Indonesia, diperkirakan terdapat 112.000 anak dengan ASD pada tahun 2013 dan diperkirakan meningkat menjadi 134.000 anak pada tahun 2015 (Judarwanto, 2011). Perkiraan peningkatan jumlah anak dengan ASD ini tentunya diikuti oleh meningkatnya perkiraan jumlah orang tua yang memiliki anak dengan ASD. Orang tua dari anak dengan ASD ini merupakan kelompok yang rentan mengalami kesejahteraan psikologis yang rendah, emosi negatif, stres, hingga depresi karena signifikannya tantangan yang dihadapi ketika merawat anak (Altiere \& Von Kluge, 2009; Craig dkk., 2016; Davis \& Carter, 2008; Dunn dkk., 2001; Lord \& Bishop, 2010; Muniroh, 2010). Selain itu juga disebutkan bahwa orang tua dari anak dengan ASD memiliki tingkat stres yang lebih tinggi dibanding orang tua dari anak dengan typically development dan anak dengan gangguan perkembangan lainnya (Craig dkk., 2016; Hayes \& Watson, 2013; Silva \& Schalock, 2012).

Beberapa tantangan yang dihadapi orang tua yang memiliki anak dengan ASD antara lain melakukan pengasuhan seumur hidup dan perlunya menyesuaikan pengasuhan dengan kondisi anak (Happé, 1994); kelekatan antara orang tua dengan anak sulit terbangun, adanya anggapan ASD sebagai aib dan beban keluarga, serta sulitnya menunjukkan kasih sayang melalui sentuhan/perhatian (Asrizal, 2016). Orang tua khususnya di Asia, mungkin akan merasakan adanya stigma dan diskriminasi yang lebih kuat terhadap anak dengan ASD karena rendahnya kesadaran teradap anak berkebutuhan khusus (Ilias dkk., 2017). Tantangan lainnya adalah mengelola pola makan, nutrisi, dan berat badan anak, karena adanya kerentanan obesitas akibat penggunaan obat-obatan tertentu (Curtin dkk., 2014); adanya respon yang berlebihan terhadap bau atau tekstur makanan, dan pilih-pilih (picky) makanan (Zobel-Lachiusa, 2016); serta gangguan tidur (Bonis, 2016) yang dapat menyebabkan kelelahan dan stres pada orang tua. Tantangan ini utamanya akan dirasakan oleh orang tua biologis karena adanya tingkat stres yang tinggi pada orang tua biologis dibanding orang tua non-biologis (Ceballo dkk., 2004).

Meskipun menghadapi tantangan yang signifikan dan adanya kerentanan mengalami stres yang dapat mengarah pada depresi (Altiere \& Von Kluge, 2009; Muniroh, 2010), namun terdapat kelompok orang tua yang mampu bangkit dari stres, melewati masa-masa sulit dalan merawat anak dengan ASD, yang akhirnya dapat memunculkan emosi positif dalam diri, memperoleh keseimbangan psikologis, dan memiliki pencapaian terhadap kemajuan anak (Zhao \& Fu, 2020). Serupa dengan hal tersebut, Bayat (2007) menunjukkan bukti adanya sejumlah orang tua yang memiliki ketahanan dan menemukan banyak aspek-aspek positif dalam merawat anak dengan ASD walaupun tantangan yang dihadapi

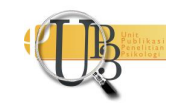


sangatlah besar. Kondisi seperti ini menunjukkan adanya kemampuan bertahan dan bangkit dari kondisi sulit yang dialami oleh orang tua dari anak dengan ASD. Kemampuan ini secara konseptual dikenal dengan istilah resiliensi.

Smith dkk. (2008) mendefinisikan resiliensi sebagai kemampuan untuk bangkit kembali atau pulih dari kondisi stres. Kemampuan resiliensi terbentuk karena adanya interaksi antara faktor protektif dengan faktor resiko. Faktor protektif oada orang tua anak dengan ASD antara lain usia anak dengan ASD, dukungan sosial, waktu sejak didiagnosis, locus of control, cognitive appraisal, spiritualitas, dan religius belief (Bekhet dkk., 2012). Sedangkan keparahan gejala ASD, kepuasan pernikahan, parents anger, dan jumlah anak dengan ASD menjadi faktor resiko orang tua (Bekhet dkk., 2012).

Resiliensi akan membantu orang tua untuk bangkit dari kesulitan dan memiliki kontrol diri (Sun \& Stewart, 2007), memiliki penerimaan terhadap diri sendiri dan penolakan yang rendah terhadap kondisi anak (Valentia dkk., 2017). Selain itu, orang tua yang resilien akan mampu mengembangkan potensi yang dimiliki anak secara optimal (Sari dkk., 2011) dan dapat mengatasi berbagai stres yang muncul dalam menjalankan tugas pengasuhan (Dewi \& Widiasavitri, 2019). Kemampuan resiliensi ini akan membuat orang tua mampu melakukan penyesuaian diri dengan kesulitan yang signifikan (Hendriani dkk., 2006). Sehingga resiliensi penting untuk ditumbuhkan dalam konteks orang tua dari anak dengan ASD karena dapat melindungi orang tua dari efek negatif yang ditimbulkan oleh kondisi stres (Reivich \& Shatte, 2002).

Kemampuan orang tua untuk berhasil menghadapi tantangan (menjadi resilien) dalam merawat anak dengan ASD sangatlah bervariasi (Altiere \& Von Kluge, 2009). Salah satu variabel psikologis yang berpotensi mempengaruhi pengalaman orang tua ini adalah self-compassion (Torbet dkk., 2019). Selfcompassion sendiri didefinisikan sebagai sikap positif terhadap diri sendiri, peduli, dan penuh kasih sayang, yang muncul ketika diri sendiri dihadapkan pada kesulitan atau merasa tidak mampu (Neff, 2003). Self-compassion dapat membantu menciptakan keseimbangan antara waktu dan energi yang dibutuhkan untuk merawat anak dengan ASD dan kebutuhan untuk perawatan emosional orang tua (Torbet dkk., 2019). Adanya self-compassion dalam diri menjadikan orang tua dari anak dengan ASD mampu menenangkan diri, memberi perhatian, serta dukungan saat menghadapi tantangan dalam menjalankan hidup. Akhirnya hal ini akan berperan dalam membantu orang tua untuk mengatasi kesulitan selama merawat anak dengan ASD.

Penelitian terdahulu telah mengungkapkan adanya korelasi antara self-compassion dengan resiliensi pada remaja (Bluth \& Eisenlohr-Moul, 2017; Bluth dkk., 2018), tenaga kesehatan dan peserta medical training (Kemper dkk., 2015; Olson \& Kemper, 2014), serta pada wanita penderita kanker payudara (Alizadeh dkk., 2018). Meskipun begitu, hasil penelitian Sünbül \& Gördesli (2020) menunjukkan tidak adanya korelasi antara self-compassion dengan resiliensi pada orang tua dengan anak berkebutuhan khusus. Di Indonesia sendiri, penelitian mengenai korelasi self-compassion dengan resiliensi telah menunjukkan hasil yang konsisten pada berbagai konteks (Dwitya \& Priyambodo, 2020; Febrinabilah \& Listiyandini, 2017; Kawitri dkk., 2019; Hatari \& Setyawan, 2018).

Penelitian mengenai pengaruh juga telah dilakukan oleh beberapa peneliti terdahulu dalam konteks remaja dengan orang tua yang bercerai (Prasetyo \& Jannah, 2005; Rachman, 2020), siswa (Bluth \& Eisenlohr-Moul, 2017), dan medical student (Priatni \& Listiyandini, 2018), namun belum ditemukan penelitian mengenai pengaruh self-compassion terhadap orang tua dari anak dengan ASD di Indonesia. Penelitian serupa telah dilakukan oleh Dwitya \& Priyambodo (2020) yang menguji korelasi antara dua variabel self-compassion dan resiliensi pada konteks ibu yang memiliki anak dengan ASD. Penelitian ini mencoba untuk menguji pengaruh self-compassion terhadap resiliensi pada konteks ayah dan ibu (orang 
tua biologis) yang memiliki anak dengan ASD. Hal ini merujuk pada pendapat Craig dkk. (2016) bahwa tantangan dalam merawat anak dengan ASD bukan hanya dirasakan oleh ibu melainkan juga ayah.

Selain dipengaruhi oleh self-compassion, resiliensi orang tua dari anak dengan ASD juga dipengaruhi oleh faktor demografis orang tua dan anak dengan ASD itu sendiri. Faktor-faktor demografis tersebut antara lain adalah usia anak dengan ASD, jumlah anak dengan ASD, keparahan gejala ASD, dan waktu sejak didagnosis (Bekhet dkk., 2012). Faktor lain yang juga berpengaruh pada resiliensi adalah usia dan jenis kelamin orang tua (Sun \& Stewart, 2007), tingkat pendidikan orang tua (Bonanno dkk., 2006), pendapatan yang cukup (Walsh, 2016), serta dukungan sosial yang diberikan kepada orang tua dari anak dengan ASD (Sarafino \& Smith, 2011). Pendapat yang berbeda diungkapkan oleh Kadi \& Cetin (2018) dimana tidak terdapat perbedaan antara jenis kelamin orang tua, dukungan yang diterima orang tua selama pengasuhan, usia orang tua, tingkat pendapatan dan pendidikan orang tua, serta usia anak terhadap skor resiliensi orang tua. Penelitian ini menunjukkan adanya inkonsistensi dengan hasil penelitian lainnya yang menunjukkan bahwa terdapat perbedaan resiliensi berdasarkan faktor demografis.

Berdasarkan paparan di atas, maka penelitian ini berusaha untuk mengetahui (1) pengaruh selfcompassion terhadap resiliensi pada orang tua yang memiliki anak dengan ASD; (2) perbedaan skor selfcompassion orang tua berdasarkan faktor demografis; dan (3) perbedaan skor resiliensi orang tua berdasarkan faktor demografis.

\section{Desain Penelitian}

\section{E T O D E}

Penelitian ini menggunakan pendekatan kuantitatif. Pendekatan kuantitatif dipilih karena tujuan penelitian ini adalah untuk mengetahui pengaruh variabel independen terhadap variabel dependen dan menguji perbedaan skor pada setiap variabel yang diteliti melalui uji hipotesis. Sehingga pendekatan kuantitatif dirasa tepat untuk mencapai tujuan tersebut (Singarimbun \& Effendi, 2006). Teknik pengumpulan data yang digunakan adalah survei dengan menggunakan kuesioner yang disebarkan secara online.

\section{Partisipan}

Partisipan dalam penelitian ini adalah orang tua (ayah dan/atau ibu) biologis yang memiliki anak dengan ASD dan berdomisili di Indonesia. Teknik sampling yang digunakan adalah purposive sampling dengan tujuan agar mendapatkan partisipan yang sesuai dengan kriteria partisipan penelitian. Penentuan jumlah sampel dilakukan menggunakan $G^{*}$ Power versi 3.1.9.4 dengan effect size medium sebesar 0.30 (Cohen, 1992). Hasil perhitungan dengan effect size ini diperoleh jumlah sampel minimal yaitu 111. Jumlah keseluruhan partisipan dalam penelitian ini adalah 132 orang tua dari anak dengan ASD. Partisipan pada penelitian ini telah mengisi informed consent dan telah menyatakan bersedia berpartisipasi dalam penelitian.

Seluruh partisipan pada penelitian ini berjumlah 132 orang tua dengan rincian $117\left(M_{\text {usia }}=2,17\right.$; $S D_{\text {usia }}=0,858 ; 87,12 \%$ perempuan/ibu). Sebagian besar partisipan berusia 31-40 tahun (46,21\%), 41-50 tahun $(24,48 \%), 20-30$ tahun $(21,96 \%), 51-60$ tahun $(8,3 \%)$. Tingkat pendidikan partisipan mayoritas S1 (51,5\%), SMA/sederajat (21,2\%), diploma (18,9\%), S2 (7,6\%), dan SD/sederajat $(0,8 \%)$. Mayoritas orang tua bergabung dalam komunitas orang tua dengan anak ASD/ABK (89,4\%). Penghasilan keluarga per bulan sebesar 0-5 juta (50,8\%), 6-10 juta (27,3\%), 11-15 juta (9,1\%), 16-20 juta (5,3\%), lebih dari 20 juta (7,6\%). Mayoritas partisipan memiliki anak dengan ASD berjenis kelamin laki-laki $(84,1 \%)$, berusia 2-6 tahun (40,15\%), dengan tingkat keparahan gejala level 1/membutuhkan dukungan (35,6\%).

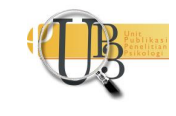


Partisipan dalam penelitian ini mewakili 18 provinsi di Indonesia yang berasal dari Pulau Sumatera, Kalimantan, Jawa, Bali, Sulawesi, dan Papua.

\section{Pengukuran}

Instrumen pengukuran dalam penelitian ini terdiri dari dua alat ukur. Self-compassion diukur menggunakan Self-compassion Scale (SCS) 26 item milik Neff (2003) yang telah diadaptasi oleh Sugianto dkk. (2020) dengan lima pilihan jawaban (1="hampir tidak pernah" hingga 5="hampir selalu"). Resiliensi diukur menggunakan Brief Resilience Scale (BRS) enam item milik Smith dkk. (2008) yang telah diterjemahkan oleh Cathlin dkk. (2019) dengan lima pilihan jawaban (1="sangat tidak setuju", $2=$ "tidak setuju", 3="netral", 4="setuju", 5="sangat setuju"). Skala yang digunakan untuk kedua variabel adalah skala likert. Skoring kedua alat ukur dilakukan dengan cara membalik item unfavorable kemudian menjumlahkan seluruh skor pada setiap subskala. SCS menghasilkan skor total sebesar 26 hingga 130, sedangkan BRS menghasilkan skor total sebesar 6 hingga 30. Skor total inilah yang kemudian digunakan dalam analisis data penelitian. Penulis juga menyertakan kuesioner demografis orang tua (usia, jenis kelamin, tingkat pendidikan, tingkat pendapatan, status pekerjaan, status pernikahan, usia ibu saat hamil anak dengan ASD, dan keikutsertaan dalam komunitas) dan anak dengan ASD (usia saat ini, jenis kelamin, usia saat terdiagnosis, level keparahan gejala) pada penelitian ini.

Hasil analisis reliabilitas dengan Cronbach's alpha untuk kedua skala pada penelitian ini menunjukkan indeks koefisien realibilitas yang sangat tinggi $(S C S=.890 ; B R S=.835)$ (Pallant, 2011). Kedua skala penelitian telah melewati uji validitas menggunakan content validity index (CVI) dan cognitive interviewing $(\mathrm{CI})$. Validitas kedua alat ukur $(\mathrm{SCS}=.97$; $\mathrm{BRS}=1)$ termasuk dalam kategori baik karena skor CVI mendekati angka 1 (Polit \& Beck, 2005). CI dilakukan pada tiga calon partisipan untuk memastikan bahwa pernyataan pada setiap alat ukur dapat dipahami oleh partisipan penelitian. Hasil CI menunjukkan bahwa pernyataan/kalimat dalam kedua alat ukur cukup jelas dipahami oleh partisipan.

\section{Analisis Data}

Teknik analisis data yang digunakan adalah uji regresi linear sederhana dan uji beda menggunakan independent sample t-test dan ANOVA. Uji regresi linear sederhana digunakan untuk menguji pengaruh satu variabel independen terdahap satu variabel dependen. Uji independent sample t-test digunakan untuk mengetahui perbedaan rata-rata antara dua kelompok yang tidak berpasangan, sedangkan uji ANOVA bertujuan untuk mengetahui ada atau tidaknya perbedaan rata-rata lebih dari dua kelompok yang tidak berpasangan. Uji asumsi diperlukan sebelum menganalisis data penelitian ini, yaitu uji normalitas, uji linearitas, dan uji heteroskedastisitas. Seluruh analisis data dalam penelitian ini dilakukan dengan bantuan SPSS 22.0 for Windows.

\section{HAS IL PENELITIAN}

Hasil analisis deskriptif menunjukkan bahwa sebagian besar partisipan memiliki skor self-compassion dengan kategori sedang sebanyak 90 orang tua $(68,18 \%)$, kategori rendah sebanyak 23 orang tua $(17,42 \%)$, dan kategori tinggi sebanyak 19 orang tua $(14,39 \%)$. Mayoritas partisipan juga menunjukkan skor resiliensi dalam kategori sedang sebanyak 89 orang tua (67,42\%), kategori tinggi sebanyak 26 orang tua $(19,69 \%)$, dan kategori rendah sebanyak 17 orang tua $(12,87 \%)$. Kategorisasi skor variabel self-compassion dan resiliensi ditentukan berdasarkan norma kategorisasi dari Azwar (2010). 
Hasil uji regresi linear sederhana menunjukkan bahwa model regesi yang dihasilkan oleh prediktor selfcompassion diketahui cocok dalam menunjukkan data $\left(F(1,13)=49,522 ; p<0,000 ; R^{2}=0,276\right)$ dan varians prediktor dapat menjelaskan $27,6 \%$ dari varians variabel dependen. Self-compassion $(B=0,180$; $S E=0,026 ; t=7,037 ; p<0,000$ ) berkorelasi positif dan kuat dalam mempengaruhi resiliensi. Selfcompassion memiliki taraf signifikansi $p=0,000$ yang menunjukkan adanya pengaruh yang signifikan antara self-compassion terhadap resiliensi orang tua dari anak dengan ASD. Resiliensi orang tua dari anak dengan ASD dalam penelitian ini dapat dijelaskan oleh self-compassion sebesar 27,6\% dan sisanya yaitu $72,4 \%$ dijelaskan oleh faktor lain yang tidak diteliti.

Penulis melakukan uji independent sample t-test untuk melihat perbedaan rata-rata self-compassion berdasarkan jenis kelamin orang tua yaitu laki-laki $(N=17 ; M=107,11 ; S D=15,62)$ dengan perempuan $(N=115 ; \quad M=92,75 ; S D=14,03)$. Hasilnya terdapat rata-rata self-compassion yang cukup besar $(t(130)=4,05 ; p=0,00 ;$ mean differences $=14,353 ; 95 \%$ CI $[7,355 ; 21,351])$ antara laki-laki dengan perempuan. Perbedaan rata-rata self-compassion berdasarkan keikutsertaan orang tua dalam komunitas orang tua dengan ABK/ASD yaitu bergabung dalam komunitas sebesar $(N=118 ; M=95,75$; $S D=14,86)$ dengan tidak bergabung dalam komunitas sebesar $(N=14 ; M=86,93 ; S D=15,14)$. Hasilnya terdapat perbedaan rata-rata self-compassion $(t(130)=2,09 ; p=0,038$; mean differences $=8,826 ; 95 \% \mathrm{CI}$ $[0,498 ; 17,154])$ antara orang tua yang bergabung dalam komunitas dengan orang tua yang tidak bergabung dalam komunitas.

Uji ANOVA dilakukan untuk menguji perbedaan rata-rata self-compassion berdasarkan tingkat usia 2030 tahun $(N=29 ; M=88,59 ; S D=18,333), 31-40$ tahun $(N=62 ; M=95,95 ; S D=13,520), 41-50$ tahun $(N=31$; $M=99,74 ; S D=11,437)$, dan 51-60 tahun $(N=10 ; M=90,60 ; S D=15,084)$. Hasil analisis menunjukkan bahwa ada perbedaan rata-rata self-compassion yang cukup besar $(F(3,128)=3,293 ; p=0,023)$ berdasarkan usia partisipan. Kemudian, terdapat perbedaan rata-rata resiliensi yang cukup besar $(F(4$, 127) $=0,760 ; p=0,023$ ) berdasarkan tingkat pendidikan SD, SMP, SMA, Diploma, S1, dan S2. Perbedaan rata-rata $(F(2,114)=6,930 ; p=0,001)$ juga ditemukan pada resiliensi berdasarkan tingkat keparahan gejala ASD level 1/membutuhkan dukungan $(N=47 ; M=21,53 ; S D=5,149)$, level 2/sangat membutuhkan dukungan $(N=46 ; M=20,83 ; S D=4,434)$, dan level 3/amat sangat membutuhkan dukungan $(N=24$; $M=17,08 ; S D=5,225)$.

Selain melakukan uji ANOVA, penulis juga melakukan post hoc test dengan Turkey HSD. Berdasarkan nilai post hoc test, diketahui bahwa terdapat perbedaan yang signifikan untuk self-compassion $\left(t(131)=3,29 ; p_{\text {turkey }}=0,020\right.$; mean difference $=11,15 ; 95 \%$ CI $\left.[-21,04 ;-1,27]\right)$ pada usia $20-30$ tahun dan 41-50 tahun. Selain itu, juga diketahui bahwa tingkat resiliensi berdasarkan keparahan gejala ASD level 2 ditemukan berbeda $\left(t(116)=6,93 ; p_{\text {turkey }}=0,08\right.$; mean difference $\left.=3,74 ; 95 \% \mathrm{CI}[0,82 ; 6,67]\right)$ dengan level 3. Tingkat resiliensi berdasarkan keparahan gejala ASD level 3 juga diketahui berbeda $(t(116)=6,93$; $p_{\text {turkey }}=0,01$; mean difference $\left.=-4,44 ; 95 \% \mathrm{CI}[-7,37 ;-1,53]\right)$ dengan level 1 dan level $2(t(116)=6,93$; $p_{\text {turkey }}=0,08 ;$ mean difference $\left.=-3,74 ; 95 \% \mathrm{CI}[-6,67 ;-0,82]\right)$.

\section{I S K U S I}

Penelitian ini bertujuan untuk menguji pengaruh self-compassion terhadap resiliensi pada orang tua anak dengan Autism Spectrum Disorder (ASD) serta mengetahui perbedaan rata-rata self-compassion dan resiliensi berdasarkan faktor demografis. Faktor demografis yang dianalisis adalah demografis orang tua (usia, jenis kelamin, keikutsertaan dalam komunitas orang tua dengan anak ASD/ABK, tingkat pendidikan, tingkat pendapatan) dan demografis anak (usia, tingkat keparahan gejala ASD). Hasil analisis data menunjukkan bahwa self-compassion memiliki pengaruh yang signifikan dan kuat terdahap

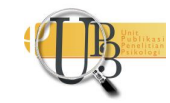


resiliensi orang tua dari anak dengan ASD. Arah hubungan antar variabel diketahui positif, yang berarti bahwa semakin tinggi self-compassion maka resiliensi juga akan semakin tinggi dan begitu pula sebaliknya.

Hasil penelitian ini sejalan dengan Bluth \& Eisenlohr-Moul (2017) yang menyebutkan bahwa selfcompassion memiliki pengaruh yang signifikan dan positif terhdap resiliensi. Neff \& Faso (2015) menemukan bahwa self-compassion merupakan salah satu faktor penting yang menjadi strategi penanggulangan bagi orang tua dari anak dengan ASD ketika dihadapkan dengan stressor terkait gangguan pada anak. Hasil penelitian tersebut menunjukkan bahwa self-compassion memiliki hubungan yang positif dengan kepuasan hidup, harapan, dan goal re-engangement (tidak menuntut sesuatu yang melebihi kemampuan) serta memiliki hubungan yang negatif dengan depresi dan stres. Self-compassion dapat membuat orang tua dari anak dengan ASD terhindar dari stres berkepanjangan (Das dkk., 2017) dan memiliki kemampuan resiliensi (Bluth \& Eisenlohr-Moul, 2017).

Tantangan signifikan yang dialami oleh orang tua dari anak dengan ASD dapat menjadi kerentanan untuk mengalami stres, gejala depresi, masalah terkait kejiwaan, dan kesejahteraan psikologis yang rendah (Cai dkk., 2020; Cohrs \& Leslie, 2017; Ingersoll \& Hambrick, 2011). Orang tua tersebut bisa saja merasakan keterpurukan ketika banyak tantangan yang muncul dari situasi yang tidak diharapkan. Hal ini menjadikan orang tua dapat merasa cemas, gagal, dan merasa tidak pantas (Neff \& McGehee, 2010).

Pada situasi yang tidak menyenangkan tersebut, peran self-compassion sangat dibutuhkan bagi orang tua. Self-compassion akan membantu orang tua untuk memiliki rasa sayang, berbaik hati, dan peduli dengan diri sendiri atas kesulitan yang terjadi. (Desiningrum dkk., 2020) mengungkapkan, ibu dari anak dengan ASD yang compassion memiliki pemikiran bahwa dirinya merupakan seorang ibu yang istimewa karena mampu menghadapi tantangan dalam merawat anak serta dapat menumbuhkan ikatan hangat antara orang tua dengan anak.

Alizadeh dkk. (2018) menyatakan bahwa individu yang memiliki kemampuan untuk berbaik hati, menyayangi diri sendiri, serta tidak melakukan self-judgment diketahui memiliki tingkat resiliensi yang lebih tinggi dibanding individu yang tidak memiliki kemampuan tersebut. Studi lain yang dilakukan oleh Kurilova (2013) menunjukkan bahwa memperlakukan diri sendiri dengan kebaikan, memberi perhatian, dan memberi dukungan saat menghadapi situasi sulit dalam hidup berperan dalam membantu individu untuk mengatasi kesulitannya. Oleh karena itu, self-compassion ini dapat membantu individu untuk mencapai kemampuan resiliensinya.

Orang tua dari anak dengan ASD yang memiliki tingkat self-compassion yang lebih tinggi ditemukan lebih tangguh dibandingkan dengan orang tua yang memiliki self-compassion rendah (Neff \& Faso, 2015). Kemampuan untuk menerima dan berbaik hati pada diri sendiri serta penuh kasih sayang dalam menghadapi kesulitan dapat membantu memberikan kekuatan yang dibutuhkan untuk melewati tantangan dalam merawat anak dengan ASD tanpa menjadi putus asa. Selain itu, self-compassion juga membantu orang tua untuk merasa tidak terbebani oleh tantangan dalam merawat anak dengan ASD. Mengingat bahwa penderitaan merupakan pengalaman manusia yang universal, orang tua dari anak dengan ASD tidak akan merasa terputus dari orang lain. Dengan demikian, self-compassion dapat memberikan penyangga yang kuat terhadap tantangan dan kesulitan yang muncul saat merawat anak dengan ASD.

Hasil analisis data selanjutnya menunjukkan bahwa resiliensi orang tua dari anak dengan ASD dijelaskan oleh self-compassion sebesar 27,6\% dan sisanya yaitu 72,4\% dijelaskan oleh faktor-faktor lain yang tidak diteliti. Faktor-faktor lain tersebut dapt berupa dukungan keluarga dan dukungan 
pasangan (Saichu \& Listiyandini, 2018) serta persepsi dukungan sosial (Ali dkk. , 2020). Selain itu, faktor lainnya adalah self-esteem (Chaerunissa, 2020; Reivich \& Shatte, 2002), harapan (Muharromah \& Hendriani, 2020), optimisme (Choirunnisa \& Supriatna, 2019), spiritualitas (Puteri, 2014), dan religiusitas (Suryaman dkk., 2013).

Berdasarkan uji beda, diketahui bahwa terdapat perbedaan rata-rata self-compassion berdasarkan usia dan jenis kelamin orang tua, keikutsertaan orang tua dalam komunitas. Selain itu ditemukan juga perbedaan rata-rata resiliensi berdasarkan tingkat pendidikan orang tua dan tingkat keparahan gejala ASD. Sementara itu, tingkat pendidikan dan penghasilan orang tua, keparahan gejala ASD dan usia anak dengan ASD tidak memiliki perbedaan rata-rata pada self-compassion. Kemudian, tidak ditemukan perbedaan rata-rata resiliensi berdasarkan usia dan jenis kelamin orang tua, tingkat penghasilan, keikutsertaan dalam komunitas, dan usia anak.

Neff (2003) menyebutkan bahwa terdapat perbedaan tingkat self-compassion pada laki-laki dengan perempuan. Perempuan ditemukan memiliki tingkat self-compassion yang lebih rendah dibanding dengan laki-laki. Temuan Neff (2003) sejalan dengan hasil penelitian ini, bahwa orang tua berjenis kelamin laki-laki memiliki rata-rata tingkat self-compassion yang lebih tinggi dibanding orang tua berjenis kelamin perempuan. Hal ini disebabkan karena perempuan cenderung lebih kritis terhadap dirinya sendiri dan cenderung merenungkan perasaan negatifnya lebih dari laki-laki. Selain itu, wanita memiliki kemungkinan lebih kecil daripada laki-laki untuk bersikap baik dan lembut terhadap diri sendiri atau untuk melihat pengalaman mereka sebagai bagian dari hal yang manusiawi (Neff, 2003)

Perbedaan rata-rata self-compassion juga ditemukan berdasarkan keikutsertaan orang tua dalam komunitas orang tua anak dengan ASD/ABK. Hal ini berkaitan dengan dukungan sosial yang diterima oleh orang tua dari anak dengan ASD. Temuan ini didukung Jeon dkk. (2016) yang menyatakan bahwa dukungan sosial ditemukan memiliki efek positif dengan self-compassion. Jeon dkk. (2016) menjelaskan bahwa dukungan sosial berperan dalam membantu mengadopsi sikap self-compassion terhadap diri sendiri. Orang lain yang memahami kesulitan seseorang dan menyikapinya dengan sikap hangat, hal ini dapat diartikan sebagai hasil dari kemampuan untuk memperlakukan diri sendiri dengan cara yang sama seperti seseorang diperlakukan oleh orang lain (Neff \& McGehee, 2010). Selain itu, bergabung dengan komunitas orang tua dari anak dengan ASD/ABK, dapat meningkatkan peluang orang tua dari anak dengan ASD untuk mendapatkan dukungan sosial dalam bentuk informational support (Malecki \& Demaray, 2002).

Uji ANOVA menunjukkan hasil yang signifikan $(p<0,05)$ pada self-compassion berdasarkan usia orang tua, yang berarti terdapat perbedaan rata-rata self-compassion berdasarkan usia orang tua. Temuan ini sejalan dengan Neff \& Vonk (2009) yang menyatakan bahwa usia dapat memprediksi tingkat selfcompassion individu secara signifikan. Semakin tinggi usia individu, maka tingkat self-compasionnya yang dimiliki juga akan semakin tinggi. Neff (2011)menjelaskan hal ini dengan teori perkembangan Erickson dan menyebutkan bahwa individu yang telah mencapai tahap integrity akan lebih mampu menerima kondisi yang terjadidalam hidupnya, sehingga hal ini mempengaruhi tingkat self-compassion yang lebih tinggi. Tahap perkembangan integrity sendiri memiliki ciri yaitu, individu dapat melakukan penerimaan diri dengan positif.

Berdasarkan uji post hoc self-compassion berdasarkan usia orang tua, diketahui bahwa terdapat perbedaan rata-rata yang signifikan pada usia 20-30 tahun dan 41-50 tahun, namun tidak terdapat perbedaan rata-rata self-compassion pada usia 31-40 tahun dan 51-60 tahun. Jika dilihat dari hasil uji post hoc didapatkan bahwa hanya dua kelompok usia yang menunjukkan adanya perbedaan rata-rata self-compassion dan kelompok ini bukanlah kelompok usia yang paling dewasa. Hasil ini menunjukkan 
bahwa pada orang tua dari anak dengan ASD, self-compassion tidak selalu meningkat seiring dengan bertambahnya usia orang tua. Hal ini diasumsikan karena adanya faktor-faktor lain yang mempengaruhi self-compassion pada dua kelompok usia ini.

Terdapat perbedaan yang signifikan $(\mathrm{p}<0,05)$ pada resiliensi berdasarkan tingkat pendidikan orang tua. Bonanno dkk. (2006) menyebutkan bahwa resiliensi diprediksi oleh beberapa faktor demografis, salah satunya adalah tingkat pendidikan. Semakin tinggi pendidikan seseorang, maka kemampuan resiliensinya pun juga akan semakin tinggi. Campbell-Sills dkk. (2009) menemukan bahwa tingkat pendidikan berkorelasi dengan resiliensi pada subjek penelitiannya. Penelitian ini mengungkapkan bahwa skor resiliensi meningkat seiring dengan tingkat pendidikan yang lebih tinggi. Campbell-Sills dkk. (2009) menjelaskan tingkat pendidikan dapat memprediksi resiliensi karena sumber daya kognitif dan material yang terdapat pada individu dengan tingkat pendidikan yang lebih tinggi berfungsi sebagai penyangga stres dan oleh karena itu dapat meningkatkan resiliensi. Sebaliknya, pendidikan yang tidak memadai atau memiliki sedikit sumber daya dapat membatasi pilihan untuk mengatasi stres dan bahkan memperburuk efek stres dalam beberapa situasi.

Tingkat pendidikan ini tidak terlepas dari kemampuan kognitif. Adanya proses pendidikan yang berjalan terus menerus menjadikan individu memiliki kemampuan dalam fungsi kognitif dan individu yang memiliki tingkat pendidikan yang tinggi mempunyai resiko lebih rendah untuk mengalami penurunan fungsi kognitif (Priasmoro, 2017). Semakin tinggi pendidikan seseorang maka pengalaman hidup yang dilalui juga semakin banyak, sehingga seseorang akan lebih siap dalam menghadapi masalah yang akan terjadi (Priasmoro, 2017). Kemampuan kognitif yang baik, mengindikasikan kemampuan analisis, kreativitas, dan pemecahan masalah yang lebih baik (Everall dkk., 2006) sehingga ini dapat membantu individu ketika berhadapan dengan permasalahan hidup. Individu dengan kemampuan kognitif yang baik seharusnya memiliki kemampuan self-help yang lebih baik (Friborg dkk., 2005). Selain itu, Holaday \& McPhearson (1997) mengungkapkan bahwa kemampuan kognitif merupakan hal penting dalam resiliensi. Kemampuan kognitif ini akan berguna untuk melepaskan pikiran dari trauma dengan memanfaatkan fantasi dan harapan yang ditumbuhkan dalam diri individu.

Tingkat keparahan gejala ASD diketahui menjadi prediktor dari resiliensi orang tua dari anak dengan ASD. Hal ini terlihat dari hasil dari uji ANOVA memperlihatkan adanya perbedaan rata-rata $(\mathrm{p}<0,05)$ skor resiliensi orang tua berdasarkan tingkat keparahan gejala ASD. (Ilias dkk., 2018) menyebutkan bahwa semakin berat keparahan gelaja ASD, maka tingkat resiliensinya akan semakin rendah. Hal tersebut didukung oleh hasil uji post hoc yang memperlihatkan bahwa terdapat perbedaan rata-rata resiliensi yang signifikan pada keparahan gelaja ASD level 1 (membutuhkan dukungan) dengan level 3 (amat sangat membutuhkan dukungan), level 2 (sangat membutuhkan dukungan) dengan level 3, serta level 3 dengan level 1 dan level 2 Temuan ini juga sejalan dengan (Hartley dkk., 2011) yang mengidentifikasi bahwa keparahan gejala ASD menjadi faktor resiko dalam merawat anak dengan ASD. Beberapa penelitian menyebutkan bahwa tingkat keparahan gejala ASD yang berkaitan dengan gangguan dan masalah perilaku anak memiliki korelasi positif dengan stres dan depresi (Lyons dkk., 2010; McStay dkk., 2014; Osborne \& Reed, 2009; Zaidman-Zait dkk., 2014). Keparahan gejala ASD yang berat akan membuat orang tua berjuang lebih keras untuk menerima diagnosis anak dan menyesuaikan diri dengan kondisi anak dengan ASD. 


\section{S I M P U L A N}

Berdasarkan analisis data yang telah dilakukan, dapat disimpulkan bahwa terdapat pengaruh yang signifikan dan positif antara self-compassion terhadap resiliensi pada orang tua dari anak dengan Autism Spectrum Disorder (ASD). Temuan ini menunjukkan bahwa semakin tinggi self-compassion orang tua, maka tingkat resiliensinya akan semakin tinggi, begitu pula sebaliknya. Kemudian, terdapat perbedaan rata-rata self-compassion berdasarkan jenis kelamin orang tua, usia orang tua, dan keikutsertaan orang tua dalam komunitas. Perbedaan rata-rata juga ditemukan pada skor resiliensi berdasarkan tingkat pendidikan orang tua dan tingkat keparahan gejala ASD. Hipotesis dalam penelitian ini diterima, yaitu terdapat pengaruh yang signifikan dan positif antara self-compassion terhadap resiliensi orang tua dari anak dengan ASD.

Saran untuk penelitian selanjutnya adalah dapat meneliti faktor lain selain self-compassion yang dapat mempengaruhi resiliensi orang tua dari anak dengan ASD seperti dukungan keluarga, dukungan pasangan, persepsi dukungan sosial, harapan, optimisme, religiusitas, spiritualitas, dan self-esteem; peneliti selanjutnya juga dapat menganalisis faktor demografis yang belum dianalisis dalam penelitian ini; mengambil partisipan lebih besar dengan persebaran wilayah yang merata; serta mengkaji terkait perbedaan resiliensi pada ibu yang bekerja dengan bu tidak bekerja dan ayah yang bekerja dengan ayah yang tidak bekerja. Selain itu, psikolog dan konselor dapat merancangn intervensi yangn dapat meningkatkan self-compassion orang tua dari anak dengan ASD. Bagi orang tua dari anak dengan ASD, dapat berlatih meningkatkan kemampuan self-compassion dan tetap baik pada diri sendiri agar tidak terus menerus terjebak dalam kondisi stres sehingga akan membantu diri sendiri untuk bangkit kembali dari situasi sulit.

\section{U C A P A N T E R I M A K A S I H}

Penulis mengucapkan terima kasih kepada Allah SWT dan sahabat penulis yang telah membantu dan memberi dukungan dalam pelaksanaan penelitian ini. Terima kasih juga penulis ucapkan pada YCHI Autism Center, Terapis Autisma, PAUD Anak Ceria, para pendidik dan terapis anak berkebutuhan khusus yang telah bersedia membantu penulis untuk menyebarkan kuesioner penelitian.

\section{DEKLARASI POTENSI TERJADINYA KONFLIK KEPENTINGAN}

Rachma Setya Isfani dan Pramesti Pradna Paramita tidak bekerja, menjadi konsultan, memiliki saham, atau menerima dana dari perusahaan atau organisasi manapun yang mungkin akan mengambil untung dari diterbitkannya naskah ini.

\section{PUSTAKA ACUAN}

Ali, M., Gazadinda, R., \& Rahma, N. (2020). Hubungan antara persepsi dukungan sosial dan resiliensi pada orang tua anak berkebutuhan khusus. JPPP - Jurnal Penelitian Dan Pengukuran Psikologi, 9(2), 102-110. https://doi.org/10.21009/jppp.092.08

Alizadeh, S., Khanahmadi, S., Vedadhir, A., \& Barjasteh, S. (2018). The relationship between resilience with self- compassion, social support and sense of belonging in women with breast cancer. Asian Pacific Journal of Cancer Prevention, 19(9), 2469-2474. https://doi.org/10.22034/APJCP.2018.19.9.2469

Altiere, M. J., \& Von Kluge, S. (2009). Searching for acceptance: Challenges encountered while raising a

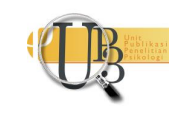


child with autism. Journal of Intellectual and Developmental Disability, 34(2), 142-152. https://doi.org/10.1080/13668250902845202

American Psychiatric Association. (2015). Diagnostic and statistical manual of mental disorder (5th ed.). American Psychiatric Association.

Asrizal. (2016). Penanganan Anak Autis dalam Interaksi Sosial. Jurnal Penelitian Kesejathteraan Sosial, 15(1), 1-8.

Azwar, S. (2010). Dasar-dasar psikometri. Pustaka Belajar Offset.

Bayat, M. (2007). Evidence of resilience in families of children with autism. Journal of Intellectual Disability Research, 51(9), 702-714. https://doi.org/10.1111/j.1365-2788.2007.00960.x

Bekhet, A. K., Johnson, N. L., \& Zauszniewski, J. A. (2012). Resilience in family members of persons with autism spectrum disorder: A review of the literature. Issues in Mental Health Nursing, 33(10), 650656. https://doi.org/10.3109/01612840.2012.671441

Bernier, R., \& Gerdts, J. (2010). Autism spectrum disorder: A reference handbook. ABC-CLIO, LLC.

Bluth, K., \& Eisenlohr-Moul, T. A. (2017). Response to a mindful self-compassion intervention in teens: A within-person association of mindfulness, self-compassion, and emotional well-being outcomes. Journal of Adolescence, 57, 108-118. https://doi.org/10.1016/j.adolescence.2017.04.001

Bluth, K., Mullarkey, M., \& Lathren, C. (2018). Self-Compassion: A Potential Path to Adolescent Resilience and Positive Exploration. Journal of Child and Family Studies, 27(9), 3037-3047. https://doi.org/10.1007/s10826-018-1125-1

Bonanno, G. A., Galea, S., Bucciarelli, A., \& Vlahov, D. (2006). Psychological Resilience After Disaster. Psychological Science, 17(3), 181-186. https://doi.org/10.1111/j.1467-9280.2006.01682.x

Bonis, S. (2016). Stress and Parents of Children with Autism: A Review of Literature. Issues in Mental Health Nursing, 37(3), 153-163. https://doi.org/10.3109/01612840.2015.1116030

Cai, R. Y., Uljarević, M., \& Leekam, S. R. (2020). Predicting Mental Health and Psychological Wellbeing in Mothers of Children with Autism Spectrum Disorder: Roles of Intolerance of Uncertainty and Coping. Autism Research, 13(10), 1797-1801. https://doi.org/10.1002/aur.2341

Campbell-Sills, L., Forde, D. R., \& Stein, M. B. (2009). Demographic and childhood environmental predictors of resilience in a community sample. Journal of Psychiatric Research, 43(12), 1007-1012. https://doi.org/10.1016/j.jpsychires.2009.01.013

Cathlin, C. A., Anggreany, Y., \& Dewi, W. P. (2019). Pengaruh Harapan Terhadap Resiliensi Wanita Dewasa Muda Yang Pernah Mengalami Abortus Spontan. Jurnal Psikologi Ulayat, 6, 1-13. https://doi.org/10.24854/jpu02019-106

Ceballo, R., Lansford, J. E., Abbey, A., \& Stewart, A. J. (2004). Gaining a child: Comparing the experiences of biological parents, adoptive parents, and stepparents. Family Relations, 53(1), 38-48. https://doi.org/10.1111/j.1741-3729.2004.00007.x

Centers for Disease Control and Prevention. (2020). Data \& statistics on autism spectrum disorder. Retrieved January 5, 2021, from cdc.gov website: https://www.cdc.gov/ncbddd/autism/data.html

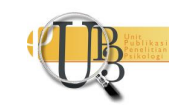


Chaerunissa, M. (2020). Pengaruh self-esteem terhadap resiliensi orang tua dengan anak berkebutuhan khusus (Universitas Negeri Jakarta). Retrieved from http://repository.unj.ac.id/10340/

Choirunnisa, K., \& Supriatna, U. Y. (2019). Hubungan antara Optimisme dan Resiliensi pada Ibu yang Memiliki Anak Penderita Leukemia di Rumah Cinta Kanker Bandung. Prosiding Psikologi, 5, 373379.

Cohen, J. (1992). A power primer. Psychological Bulletin, 112(1), 155-159. https://doi.org/10.1037/0033-2909.112.1.155

Cohrs, A. C., \& Leslie, D. L. (2017). Depression in Parents of Children Diagnosed with Autism Spectrum Disorder: A Claims-Based Analysis. Journal of Autism and Developmental Disorders, 47(5), 14161422. https://doi.org/10.1007/s10803-017-3063-y

Craig, F., Operto, F. F., De Giacomo, A., Margari, L., Frolli, A., Conson, M., ... Margari, F. (2016). Parenting stress among parents of children with Neurodevelopmental Disorders. Psychiatry Research, 242, 121-129. https://doi.org/10.1016/j.psychres.2016.05.016

Curtin, C., Jojic, M., \& Bandini, L. G. (2014). Obesity in children with autism spectrum disorder. Harvard Review of Psychiatry, 22(2), 93-103. https://doi.org/10.1097/HRP.0000000000000031

Das, S., Das, B., Nath, K., Dutta, A., Bora, P., \& Hazarika, M. (2017). Impact of stress, coping, social support, and resilience of families having children with autism: A North East India-based study. Asian Journal of Psychiatry, 28, 133-139. https://doi.org/10.1016/j.ajp.2017.03.040

Davis, N. O., \& Carter, A. S. (2008). Parenting stress in mothers and fathers of toddlers with autism spectrum disorders: Associations with child characteristics. Journal of Autism and Developmental Disorders, 38(7), 1278-1291. https://doi.org/10.1007/s10803-007-0512-z

Desiningrum, D. R., Suhariadi, F., \& Suminar, D. R. (2020). Compassion pada Pengasuhan Anak dengan $\begin{array}{lllll}\text { Autism Spectrum } & \text { Disorder. }\end{array}$ https://doi.org/10.22146/buletinpsikologi.45926

Dewi, C. P. D. C., \& Widiasavitri, P. N. (2019). Resiliensi ibu dengan anak autisme. Jurnal Psikologi Udayana, 6(01), 193. https://doi.org/10.24843/jpu.2019.v06.i01.p19

Dunn, M. E., Burbine, T., Bowers, C. A., \& Tantleff-Dunn, S. (2001). Moderators of Stress in Parents of Children with Autism. Community Mental Health Journal, 37(1), 39-52. https://doi.org/10.1023/A:1026592305436

Dwitya, K. N., \& Priyambodo, B. A. (2020). Hubungan Self-Compassion Dan Resiliensi Pada Ibu Dengan Anak Autisme. Seminar Nasional Psikologi UM, 221-229. Retrieved from http://conference.um.ac.id/index.php/psi/article/view/34

Everall, R. D., Jessica Altrows, K., \& Paulson, B. L. (2006). Creating a future: A study of resilience in suicidal female adolescents. Journal of Counseling and Development, 84(4), 461-470. https://doi.org/10.1002/j.1556-6678.2006.tb00430.x

Febrinabilah, R., \& Listiyandini, R. A. (2017). Hubungan Antara Self-Compassion dengan Resiliensi pada Mantan Pecandu. Prosiding konferensi nasional peneliti muda psikologi indonesia, 1(1), 19-28.

Friborg, O., Barlaug, D., Martinussen, M., Rosenvinge, J. H., \& Hjemdal, O. (2005). Resilience in relation to

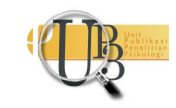


personality and intellegency. International Journal of Methods in Psychiatrics Research, 14(1), 2942. https://doi.org/10.1002/mpr.15

Hallahan, D. P., \& Kauffman, J. M. (2011). Handbook of special education. Routledge.

Happé, F.G.E, F. (1994). An advanced test of theory of mind: Understanding of story characters' thoughts and feelings by able autistic, mentally handicapped, and normal children and adults.J Autism Dev Disord 24, 129-154. https://doi.org/10.1007/BF02172093.

Hartley, S. L., Barker, E. T., Seltzer, M. M., Greenberg, J. S., \& Floyd, F. J. (2011). Marital satisfaction and parenting experiences of mothers and fathers of adolescents and adults with autism. American Journal on Intellectual and Developmental Disabilities, 116(1), 81-95. https://doi.org/10.1352/1944-7558-116.1.81

Hatari, S., \& Setyawan, I. (2018). Hubungan Antara Self Compassion Dengan Resiliensi Pada Mahasiswa Yang Sedang Mengerjakan Skripsi Di Fakultas Psikologi Universitas Diponegoro. Empati, 7(1), 5459.

Hayes, S. A., \& Watson, S. L. (2013). The impact of parenting stress: A meta-analysis of studies comparing the experience of parenting stress in parents of children with and without autism spectrum disorder. Journal of Autism and Developmental Disorders, 43(3), 629-642. https://doi.org/10.1007/s10803-012-1604-y

Hendriani, W., Handariyati, R., \& Sakti, T. M. (2006). Penerimaan Keluarga Terhadap Individu yang Mengalami Keterbelakangan Mental. Insan, 8(2), 100-103.

Holaday, M., \& McPhearson, R. W. (1997). Resilience and severe burns. Journal of Counseling and Development, 75(5), 346-356. https://doi.org/10.1002/j.1556-6676.1997.tb02350.x

Ilias, K., Cornish, K., Kummar, A. S., Park, M. S. A., \& Golden, K. J. (2018). Parenting stress and resilience in parents of children with autism spectrum disorder (ASD) in Southeast Asia: A systematic review. Frontiers in Psychology, 9(APR). https://doi.org/10.3389/fpsyg.2018.00280

Ilias, K., Liaw, J. H. J., Cornish, K., Park, M. S. A., \& Golden, K. J. (2017). Wellbeing of mothers of children with "A-U-T-I-S-M" in Malaysia: An interpretative phenomenological analysis study. Journal of Intellectual and Developmental Disability, 42(1), https://doi.org/10.3109/13668250.2016.1196657

Ingersoll, B., \& Hambrick, D. Z. (2011). The relationship between the broader autism phenotype, child severity, and stress and depression in parents of children with autism spectrum disorders. Research in Autism Spectrum Disorders, 5(1), 337-344. https://doi.org/10.1016/j.rasd.2010.04.017

Jeon, H., Lee, K., \& Kwon, S. (2016). Investigation of the structural relationships between social support, self-compassion, and subjective well-being in Korean elite student athletes. Psychological Reports, 119(1), 39-54. https://doi.org/10.1177/0033294116658226

Judarwanto, W. (2011). Perilaku makan anak sekolah. Kemenkes RI.

Kadi, S., \& Cetin, M. E. (2018). Investigating the resilience levels of parents with children with multiple disabilities based on different variables. European Journal of Educational Research, 7(2), 211-223.

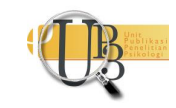


Kawitri, A. Z., Rahmawati, B. D., Arruum, R., \& Rahmatika, R. (2019). Self-Compassion and Resilience among Adolescents Living at Social Shelters. Jurnal Psikogenesis, 7(1), 76-83.

Kemper, K. J., Mo, X., \& Khayat, R. (2015). Are mindfulness and self-compassion associated with sleep and resilience in health professionals? Journal of Alternative and Complementary Medicine, 21(8), 496-503. https://doi.org/10.1089/acm.2014.0281

Kogan, M. D. (2018). The Prevalence of Parent- Reported Autism Blumberg, S. J. (2020). The Prevalence of Parent- Reported Autism Spectrum Disorder Among US Children. 142(6).Spectrum Disorder Among US Children. 142(6).

Kurilova, J. (2013). Exploration of Resilience in Relation to Mindfulness, Self-Compassion, and Attachment Styles. https://doi.org/10.11575/PRISM/26075

Lindgren, S., \& Doobay, A. (2011). Evidence-based intervention for autism spectrum disorder. Iowa Department of Human Service.

Lord, C., \& Bishop, S. (2010). Autism Spectrum Disorders: Diagnosis, Prevalence, and Services for Children and Families. Social Policy Report. Volume 24, Number 2. Social Policy Report, 24(2).

Lyons, A. M., Leon, S. C., Phelps, C. E. R., \& Dunleavy, A. M. (2010). The impact of child symptom severity on stress among parents of children with asd: The moderating role of coping styles. Journal of Child and Family Studies, 19(4), 516-524. https://doi.org/10.1007/s10826-009-9323-5

Malecki, C. K., \& Demaray, M. K. (2002). Measuring perceived social support: Development of the Child and Adolescent Social Support Scale (CASSS). Psychology in the Schools, 39(1), 1-18. https://doi.org/10.1002/pits.10004

McStay, R. L., Dissanayake, C., Scheeren, A., Koot, H. M., \& Begeer, S. (2014). Parenting stress and autism: The role of age, autism severity, quality of life and problem behaviour of children and adolescents with autism. Autism, 18(5), 502-510. https://doi.org/10.1177/1362361313485163

Muharromah, R., \& Hendriani, W. (2020). Hubungan antara Harapan (Hope) dengan Resiliensi Terhadap Istri yang Mengalami Involuntary Childless. INSAN Jurnal Psikologi Dan Kesehatan Mental, 4(1), 19. https://doi.org/10.20473/jpkm.v4i12019.19-27

Muniroh, S. M. (2010). Dinamika Resiliensi Orang Tua Anak Autis. Jurnal Penelitian, 7(9), 1-11.

Neff, K. (2003). Self-Compassion: An Alternative Conceptualization of a Healthy Attitude Toward Oneself. Self and Identity, 2(2), 85-101. https://doi.org/10.1080/15298860309032

Neff, K. D. (2011). Self-compassion, self-esteem, and well-being. Social and Personality Psychology Compass, 5(1), 1-12. https://doi.org/10.1111/j.1751-9004.2010.00330.x

Neff, K. D., \& Faso, D. J. (2015). Self-Compassion and Well-Being in Parents of Children with Autism. Mindfulness, 6(4), 938-947. https://doi.org/10.1007/s12671-014-0359-2

Neff, K. D., \& McGehee, P. (2010). Self-compassion and psychological resilience among adolescents and young adults. Self and Identity, 9(3), 225-240. https://doi.org/10.1080/15298860902979307

Neff, K. D., \& Vonk, R. (2009). Self-compassion versus global self-esteem: Two different ways of relating to oneself. Journal of Personality, 77(1), 23-50. https://doi.org/10.1111/j.14676494.2008.00537.x

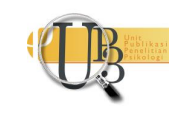


Olson, K., \& Kemper, K. J. (2014). Factors Associated With Well-being and Confidence in Providing Compassionate Care. Journal of Evidence-Based Complementary and Alternative Medicine, 19(4), 292-296. https://doi.org/10.1177/2156587214539977

Osborne, L., \& Reed, P. (2009). The relationship between parenting stress and behavior problems of children with autistic spectrum disorders. Exceptional Children, 76(1), 54-73. https://doi.org/10.1177/001440290907600103

Pallant, J. (2011). SPSS survival manual: A step by step guide to data analysis using SPSS 4th edition. Allen \& Unvin.

Polit, D. F., \& Beck, C. T. (2005). The content validity index: Are you sure you know what's being reported? critique and recommendations. 488-495. https://doi.org/10.1002/nur.20147

Prasetyo, B., \& Jannah, L. M. (2005). Metode penelitian kuantitatif: Teori dan Aplikasi. PT RajaGrafindo Persada.

Priasmoro, D. P. (2017). Pengaruh Kemampuan Personal Terhadap Resiliensi (Studi Pada Orang Tua Yang Memiliki Anak Down Syndrome). Jurnal Kesehatan Hesti Wira Sakti, 5(1), 7-11.

Priatni, M. R., \& Listiyandini, R. A. (2018). The influence of self compassion toward resilience among medical students. International Conference The 1st South East Asia Regional Conference of Psychology (RCP) 2017.1.

Puteri, M. (2014). Pengaruh spiritualitas terhadap resiliensi pada orang tua dari anak berkebutuhan khusus (Universitas Pelita Harapan). Retrieved from http://repository.uph.edu/689/

Rachman, M. F. (2020). Pengaruh self-compassion terhadap resiliensi remaja dengan orang tua yang bercerai (Universitas Airlangga). Retrieved from http://repository.unair.ac.id/98211/

Reivich, K., \& Shatte, A. (2002). The resilience factor: 7 essential skill for overcoming life's inevitable obstacle. Broodway Books.

Saichu, A. C., \& Listiyandini, R. A. (2018). Pengaruh Dukungan Keluarga dan Pasangan terhadap Resiliensi Ibu yang Memiliki Anak dengan Spektrum Autisme. Psikodimensia. 17(1), 1-9.

Sarafino, E. P., \& Smith, T. W. (2011). Health psychology: Biopsychosocial interactions (7th ed.). John Wiley and Sons.

Sari, Y., Mardiawan, O., \& Prakoso, H. (2011). Profil 'Resilience' pada Ibu yang Memiliki Anak Autis. Mimbar: Jurnal Sosial dan Pembangunan, 27(1) 105-111.

Silva, L. M. T., \& Schalock, M. (2012). Autism parenting stress index: Initial psychometric evidence. Journal of Autism and Developmental Disorders, 42(4), 566-574. https://doi.org/10.1007/s10803011-1274-1

Singarimbun, M., \& Effendi, S. (2006). Metode Penelitian Survei (editor). LP3ES.

Smith, B. W., Dalen, J., Wiggins, K., Tooley, E., Christopher, P., \& Bernard, J. (2008). The brief resilience scale: Assessing the ability to bounce back. International Journal of Behavioral Medicine, 15(3), 194-200. https://doi.org/10.1080/10705500802222972

Sugianto, D., Suwartono, C., \& Sutanto, S. H. (2020). Reliabilitas dan validitas Self-Compassion Scale versi

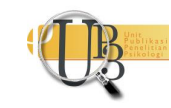


Bahasa Indonesia. Jurnal Psikologi Ulayat, 7(2), 177-191. https://doi.org/10.24854/jpu107

Sun, J., \& Stewart, D. (2007). Age and Gender Effects on Resilience in Children and Adolescents. International Journal of Mental Health Promotion, 9(4), 16-25. https://doi.org/10.1080/14623730.2007.9721845

Sünbül, Z. A., \& Gördesli, M. A. (2020). Self-compassion and Resilience in Parents of Children with Special Needs: The Mediating Role of Hope. Çukurova Üniversitesi Ĕ̆itim Fakültesi Dergisi, 49(2), 690-705.

Suryaman, M. A., Stanislaus, S., \& Mabruri, M. I. (2013). Pengaruh religiusitas terhadap resiliensi pada pasien rehabilitasi narkoba yayasan rumah damai semarang. Developmental and Clinical Psychology, 2(1), 21-27.

Thompson, J. (2013). Toddlercare: Pedoman merwat balita. Erlangga.

Torbet, S., Proeve, M., \& Roberts, R. M. (2019). Self-Compassion: a Protective Factor for Parents of Children with Autism Spectrum Disorder. Mindfulness, 10(12), 2492-2506. https://doi.org/10.1007/s12671-019-01224-5

Valentia, S., Sani, R., \& Anggreany, Y. (2017). Hubungan Antara Resiliensi Dan Penerimaan Orangtua Pada Ibu Dari Anak Yang Terdiagnosis Autism Spectrum Disorder (Asd). Jurnal Psikologi Ulayat, 4(1), 43. https://doi.org/10.24854/jpu12017-79

Walsh, F. (2016). Family resilience: a developmental systems framework. European Journal of Developmental Psychology, 13(3), 313-324. https://doi.org/10.1080/17405629.2016.1154035

Zaidman-Zait, A., Mirenda, P., Duku, E., Szatmari, P., Georgiades, S., Volden, J., ... Thompson, A. (2014). Examination of bidirectional relationships between parent stress and two types of problem behavior in children with autism spectrum disorder. Journal of Autism and Developmental Disorders, 44, 1908-1917. https://doi.org/10.1007/s10803-014-2064-3

Zhao, M., \& Fu, W. (2020). The resilience of parents who have children with autism spectrum disorder in China: a social culture perspective. International Journal of Developmental Disabilities, 0(0), 112. https://doi.org/10.1080/20473869.2020.1747761

Zobel-Lachiusa, J. (2016). Sensory Differences and Mealtime Behavior in Children With Autism. American Journal of Occupational Therapy, 70(4_Supplement_1), $7011505096 \mathrm{p} 1$. https://doi.org/10.5014/ajot.2016.70s1-rp401c 